\title{
Circular training as a means for improving physical skills in future security specialists in higher education institutions of Ukraine
}

\author{
Pryimakov O.O. ${ }^{1 \mathrm{ABDE}}$, Kyslenko D.P. ${ }^{2 \mathrm{BCE}}$, Yukhno Y.O. ${ }^{\text {BCDD }}$, Eider E. ${ }^{1 \mathrm{DE}}$ \\ ${ }^{\prime}$ Faculty of Physical Culture and Health Promotion, Szczecin University, Szczecin, Poland. \\ ${ }^{2}$ Institute of the Department of State Guard of Ukraine, Taras Shevchenko National University of Kyiv, Kyiv, Ukraine. \\ ${ }^{3}$ National University of Physical Education and Sport of Ukraine, Kyiv, Ukraine.
}

Authors' Contribution: A - Study design; B - Data collection; C - Statistical analysis; D - Manuscript Preparation; E - Funds Collection.

\begin{abstract}
Purpose: $\quad$ The battle training of military students is ineffective when limited to the knowledge of military equipment and ability to use it. The research theoretically and experimentally justifies how circular training can improve physical skills in future security specialists in HEls of Ukraine.

Material: $\quad$ The experiment involved a group of 7 respondents (aged between 21 and 23) of the Institute of the Department of State Guard of Ukraine. The methods of circular training were used to improve physical skills in future security specialists in HEls of Ukraine.

Results: $\quad$ The system of CrossFit training improves physical fitness of students and strengthens their motivation towards physical education and sport. Also it familiarizes them with modern approaches to organizing independent physical training. Circular training, in turn, contributes to the kinetic and emotional density of training, making it more diverse and engaging. Moreover, it enhances individual initiative and, therefore, increases motivation towards physical education.

Conclusions: Circular training gives positive results and successfully improves general physical fitness of military students. Keywords: Crossfit program, physical fitness, physical training, military personnel, WOD Complex.
\end{abstract}

\section{Introduction}

The armed conflicts and geopolitical challenges indicate that the national security of Ukraine is essential to social and political life of this country. The defence of national interests is a prerequisite for the state survival. Thus, the state leaders and the public pay special attention to the combat readiness and defence capabilities. Due to recent events in the near abroad, the reforming of the Armed Forces of Ukraine is accelerating. In this regard, physical training of personnel in the development of a new form of the Armed Forces of Ukraine is a toppriority. It is a comprehensive system aimed at training healthy servicemen able to solve military professional tasks. A special place is given to physical training of future officers in the Institute of the Department of State Guard of Ukraine $[1,2,3]$.

In addition, the battle training of military students is ineffective when limited to the knowledge of military equipment and ability to use it [2,4]. The successful completion of combat mission largely depends on lawenforcement officers and other military formations. The effective use of all military power of military equipment contributes to this process, too $[5,6]$. However, there is no experimental data how to improve physical skills of military students $[7,8,9]$. In this regard, the problem of developing a technique for improving the physical qualities of military personnel is relevant. This will optimize the educational process in the context of guard activity. It will also enhance the efficiency of fulfilment of operational and combat tasks of servicemen.

Many believe that one can improve motion qualities

(c) Pryimakov O.O., Kyslenko D.P., Yukhno Y.O., Eider E., 2019

doi:10.15561/20755279.2019.0508 through providing a higher quality of pedagogical management $[1,10,11]$.

CrossFit training is promoted as both physical exercise philosophy and a competitive fitness sport. They include interval training, weightlifting, plyometrics, powerlifting, gymnastics, calisthenics, strongman, etc. [12, 13, 14]. This training is practiced by the members of over 13,000 affiliated gyms. Interestingly, most of them are located in the United States, as well as people who do daily workouts [15].

It is proved $[2,16,17]$ that those methods and tools aimed at improving physical skills can intensify the educational and training process.

The research aims to theoretically and experimentally justify how circular training can improve physical skills of future security specialists in HEIs of Ukraine.

\section{Material and methods}

Participants.

The experiment involved a group of 7 students from the Institute of the Department of State Guard of Ukraine.

\section{Research Design.}

Relevant research methods were used to solve certain problems. They include analysis; pedagogical observation; pedagogical testing; pedagogical experiment; questioning; anthropometry; questionnaire; mathematical statistics. To increase the effectiveness of the training process, a special programme for physical training was designed. It is based on the methodology which incorporates the CrossFit method.

CrossFit has already proven to be rather effective. The number of military units abroad that use it for the training of fighters is steadily increasing. Many believe 
that the CrossFit with its various loads can enhance the effectiveness of such training.

The main advantage of the programme lies in its universality. Trainings are constructed cyclically, so that the type of load constantly changes due to high-intensity functional exercises. The programme combines strength exercises with bars and weights, exercises on the crossbar, jumps, running, etc. CrossFit is aimed at making a person stronger, more endurable, more coordinated and agile. This is provided by a variety of exercises, which makes the programme both interesting and challenging. It is maximally functional and varied, based on the Workout of the day (WOD). The latter is a day's task, which allowed it to be included in the programme of physical training of students. The list of daily exercises combine strength exercises, gymnastics, cardio loads. They can also include their mixed variations and directions in accordance with the physical training programme. We have defined the concept of WOD:

1. Performance of a certain work (without fixed time).

2. Performance of a large amount of work for a fixed time.

3. Performance of a fixed work for a minimum amount of time.

The WOD can include from 2 to 10 exercises and from 3 to 10 circles, namely, the more exercises, the less circles, and vice versa. The approximate WOD content for students covers gymnastics and athletic training:

WOD Complex (8 consecutive exercises in 4 rounds):

1. Pull-ups;

2. Push-ups on cross bars;

3. Shuttle run $10 \times 10 \mathrm{~m}$;

4. Lifting legs from the position of hanging on the crossbar;

5. Pushing up;

6. Simultaneous lifting of the body and legs from the position of lying on the back;

7. Step-test;

8. Jump up from place.

Physical training based on CrossFit has more significant advantages than the interval (circular) training. It is an intensive method of specialized training implying a temporary change of workstations. Each station includes exercises (or special movements) for a specific muscle group for a certain period of time. Stations can be power (simulators), gymnastics (apparatus), aerobic (running, swimming, jumping), mixed. The interval training aims to prepare the body for a limited period of time to perform the work of high intensity. It is rather necessary for sports competitions. In addition, this type of training has a strict time limit for the number of circles (attempts, rest). It must be noted that high-intensity training with maximum functionality is especially in demand. Training and practice built on the CrossFit training system can diversify the learning process. They can also enhance the motivation of military personnel towards physical training and extracurricular physical activities.

It is rather essential to optimize professional training of future security specialists in HEIs of Ukraine.
This constantly puts forward new and more complex methodological problems $[18,19]$. One of them is to improve the quality of managerial teacher activity in the training process. It is related primarily to choosing the optimal control strategy.

To solve this problem, we have developed a methodology for improving physical skills of future security specialists in Ukraine [16]. We have also conducted a pedagogical experiment to identify the effectiveness of the proposed methodology.

The training sessions lasted 2.5 months. The duration of the training session is 80 minutes. Every 15 minutes are spent on the physical training program using the CrossFit method.

The level of physical fitness (PF) was evaluated based on the results of pull-ups, push-ups, shuttle run 10x10m (SR), lifting to the crossbar, pushing up. The parameters of students' functional state were registered based on the heart rate (HR).

The effectiveness of the proposed methodology was determined due to comparing all registered before the beginning of the experiment: 1) before the experiment; 2) after 5 weeks of training; 3 ) after the experiment.

At the end of the experiment, the control index was reassigned for the students of the Institute of the Department of State Guard of Ukraine.

Statistical Analysis.

Standard statistical methods (Statistica 10.0 [20], Excel 16 programme) were used to process the experimental material.

\section{Results.}

The methodological basis of this research is the position and principles of system and complex approaches [19]. From these positions, professional activities of future security specialists depend on a number of interrelated factors. It is characterized by high physical activity and psychological stress. In addition, it requires that the personnel should demonstrate permanent moral, political, military, mental and physical fitness to perform official duties. As a result, physical training of students, future officers and officers is fundamental for successful professional activities.

The analysis of the final control indexes during shows that there is a statistically significant change in the functional indexes of the servicemen (table 1).

A statistically significant reduction of $\mathrm{HR}$ at rest at the end of the experiment indicates bradycardia and the economy of the heart functioning and its hypertrophy.

The graphical representation of HR during the experiment reflects the positive nature of adaptive changes in the heart functioning. Indeed, HR is linearly and reliably reduced from the beginning to the end of the experiment.

Correlation analysis shows that the values of $\mathrm{HR}$ at rest are statistically interrelated with its importance in muscle activity (table 2).

The analysis of reliable interrelations shows that the increase in HR at rest accelerates the cardiac reactivity to physical activity. During warming-up and physical 
Table 1. The main indexes characterizing the functionality of a WOD complex ( 3 circles) during 15 minutes before, during and at the end of the pedagogical experiment

\begin{tabular}{|c|c|c|c|c|c|c|c|c|c|}
\hline \multirow[b]{2}{*}{$\begin{array}{l}\text { 을 } \\
\stackrel{\circ}{2}\end{array}$} & \multirow[b]{2}{*}{ 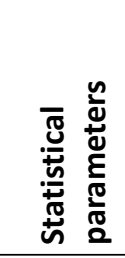 } & \multicolumn{4}{|c|}{ Heart rate in different states, bpm $^{-1}$} & \multicolumn{4}{|c|}{ Increase of heart rate, \% } \\
\hline & & 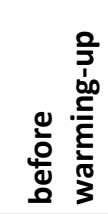 & 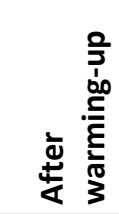 & after lo & $1 \mathrm{~min}$. & $3 \mathrm{~min}$. & 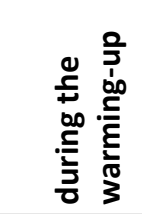 & 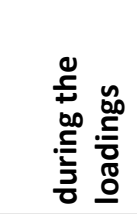 & 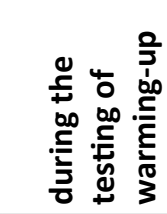 \\
\hline \multirow{4}{*}{ 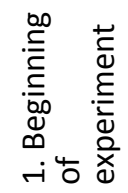 } & $x$ & 75.4 & 156.0 & 189.1 & 152.6 & 120.6 & 107.1 & 151.2 & 21.3 \\
\hline & $\pm m$ & 1.31 & 1.56 & 2.15 & 1.47 & 1.61 & 3.15 & 5.92 & 1.99 \\
\hline & $\pm \sigma$ & 3.21 & 3.83 & 5.27 & 3.60 & 3.95 & 7.72 & 14.50 & 4.88 \\
\hline & $\mathrm{n}$ & 7 & 7 & 7 & 7 & 7 & 7 & 7 & 7 \\
\hline \multirow{4}{*}{ 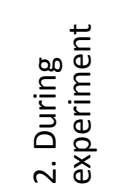 } & $x$ & 72.9 & 152.0 & 182.9 & 146.0 & 115.3 & 108.9 & 151.4 & 20.6 \\
\hline & $\pm m$ & 1.23 & 3.59 & 1.32 & 1.33 & 1.22 & 6.25 & 4.89 & 2.70 \\
\hline & $\pm \sigma$ & 3.02 & 8.79 & 3.24 & 3.27 & 2.98 & 15.32 & 11.97 & 6.62 \\
\hline & $\mathrm{n}$ & 7 & 7 & 7 & 7 & 7 & 7 & 7 & 7 \\
\hline \multirow{4}{*}{ 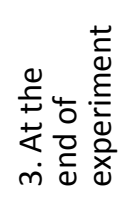 } & $x$ & 68.6 & 142.3 & 176.0 & 140.6 & 110.9 & 107.6 & 156.9 & 23.8 \\
\hline & $\pm m$ & 1.13 & 2.42 & 1.33 & 1.31 & 1.14 & 3.49 & 3.75 & 1.93 \\
\hline & $\pm \sigma$ & 2.76 & 5.94 & 3.27 & 3.21 & 2.79 & 8.55 & 9.19 & 4.72 \\
\hline & $n$ & 7 & 7 & 7 & 7 & 7 & 7 & 7 & 7 \\
\hline \multicolumn{2}{|c|}{$t_{1-2}$} & 1.43 & 1.02 & 2.49 & 3.31 & 2.61 & -0.27 & -0.02 & 0.21 \\
\hline \multicolumn{2}{|l|}{$p$} & $>0.05$ & $>0.05$ & $<0.05$ & $<0.02$ & $<0.05$ & $>0.05$ & $>0.05$ & $>0.05$ \\
\hline \multicolumn{2}{|l|}{$t_{1-3}$} & 3.97 & 4.76 & 5.19 & 6.10 & 4.92 & -0.12 & -0.82 & -0.91 \\
\hline \multicolumn{2}{|c|}{$p$} & $<0.01$ & $<0.01$ & $<0.01$ & $<0.001$ & $<0.01$ & $>0.05$ & $>0.05$ & $>0.05$ \\
\hline \multicolumn{2}{|l|}{$t_{2-3}$} & 2.56 & 2.24 & 3.65 & 2.90 & 2.65 & 0.18 & -0.90 & -0.98 \\
\hline \multicolumn{2}{|l|}{$p$} & $<0.05$ & $>0.05$ & $<0.01$ & $<0.05$ & $<0.05$ & $>0.05$ & $>0.05$ & $>0.05$ \\
\hline
\end{tabular}

Table 2. Interrelations of heart rate in different states before and in the process of muscular activity

\begin{tabular}{|c|c|c|c|c|c|c|c|}
\hline Indicators: & 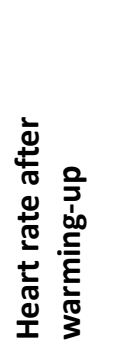 & 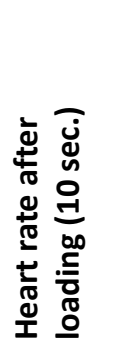 & 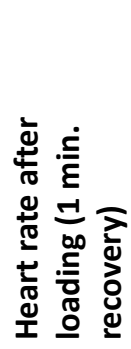 & 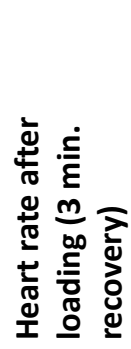 & 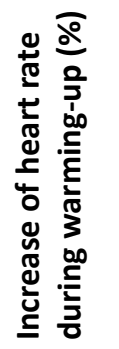 & 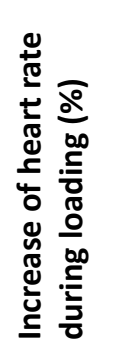 & 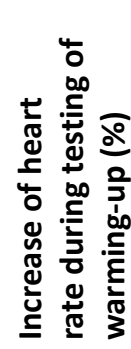 \\
\hline Heart rate before warming-up & $0.610 *$ & $0.558 *$ & $0.582 *$ & $0.597 *$ & -0.418 & $-0.872 *$ & -0.343 \\
\hline Heart rate after warming-up & & $0.617^{*}$ & 0.719* & $0.604 *$ & $0.464 *$ & -0.251 & $-0.770 *$ \\
\hline Heart rate after loading (10 sec.) & & & $0.940 *$ & $0.908^{*}$ & 0.074 & 0.112 & 0.023 \\
\hline Heart rate after loading (1 min.) & & & & $0.887^{*}$ & 0.164 & 0.038 & -0.154 \\
\hline After loading (3 min.) & & & & & 0.016 & -0.005 & -0.029 \\
\hline $\begin{array}{l}\text { Increase of heart rate during warming-up } \\
(\%)\end{array}$ & & & & & & $0.556^{*}$ & $-0.507^{*}$ \\
\hline Increase of heart rate during loading & & & & & & & $0.433^{*}$ \\
\hline
\end{tabular}

*-statistically reliable interrelations.

loading, they are $\mathrm{r}=0.610, \mathrm{p}<0.05$ and $\mathrm{r}=0.558, \mathrm{p}<0.05$ respectively. In case of the decrease, its size decreases during the experiment and loading. This reflects the growth of economization in the functioning of the body and the heart. Given the absolute values of the decrease in
HR before and during the experiment, it increases during the loading and vice versa $(\mathrm{r}=-0.872, \mathrm{p}<0.0001)$.

The graphical and mathematical model of this dependence is presented in the following figure (Figure $1)$. 


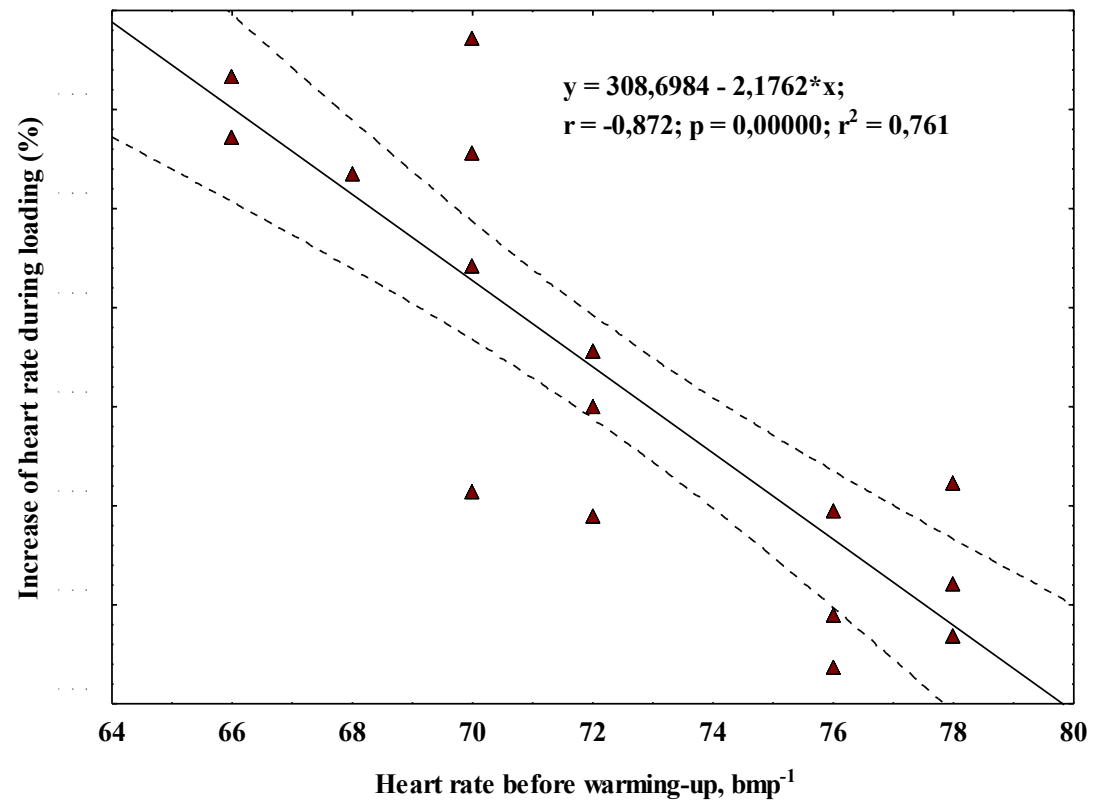

Figure 1. Regression model of dependence of Increase of heart rate during loading (\%) from heart rate before warmingup.

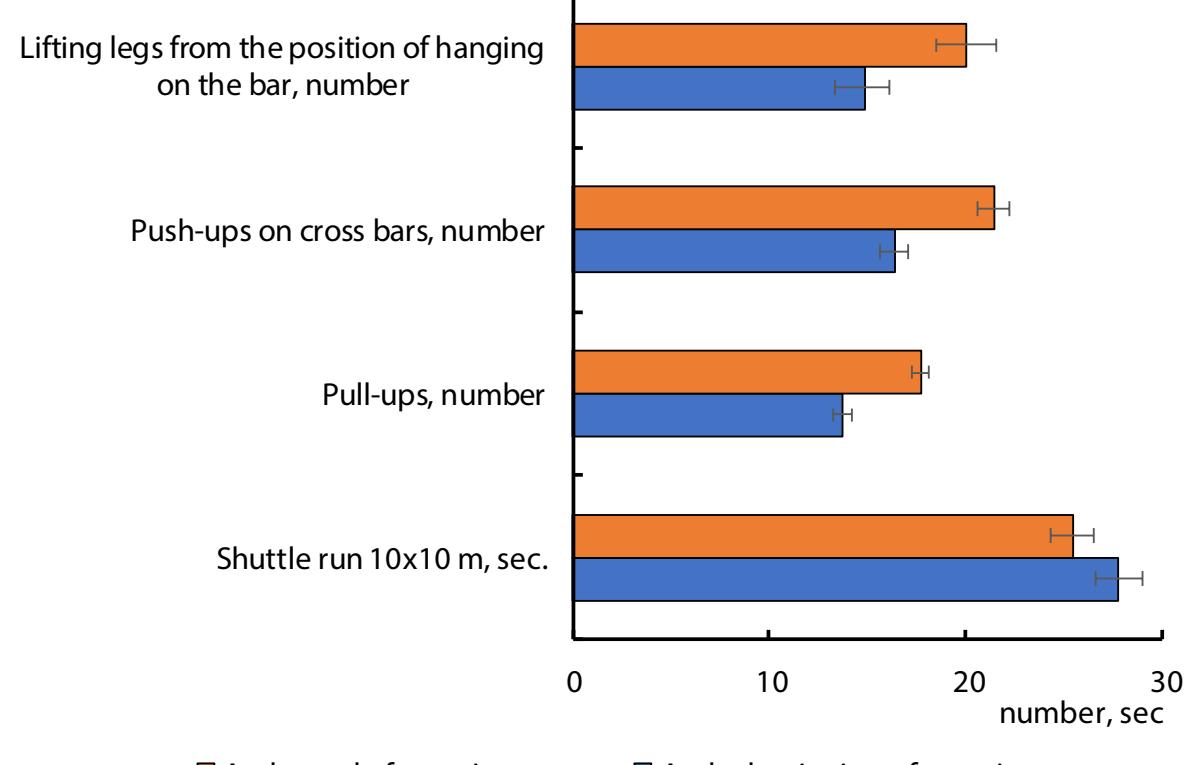

Figure 2. Indexes of physical fitness of the students before and after the pedagogical experiment

The experimental programme was aimed at increasing the level of physical fitness in the students. Therefore, the changes and interrelations between its indicators and the level of functional fitness were also analyzed.

The results of the students' physical fitness before and after the experiment are presented in Figure 2. They indicate the improvement of their physical skills due to the proposed training programme.

The data presented in Figure 2 reflect the most dominated and statistically significant changes during pull-ups $(29.2 \%, \mathrm{p}<0.01)$ and push-ups $(30.5 \%, \mathrm{p}<0.05)$.

The result in shuttle run has significantly improved
$(-8.3 \%, \mathrm{p}<0.01)$. It integrally reflects the improvement of movement coordination when transferring an object with maximum speed. It also reflects an improvement in the quality of dexterity.

When lifting legs from the position of hanging on the bar, only a positive trend emerged. It reflects the increased strength endurance during the experiment. The inauthenticity of the obtained results can be explained by a small selection of students and a high variation of the test results. They are as follows: $32.8 \%$ and $34.2 \%$, accordingly, before and after the experiment.

The correlation analysis of the interrelations between 
physical fitness indexes and the level of HR in different states shows some relevant results. Thus, the results of pull-ups and the time of the shuttle run are most strongly interrelated with all the indexes (Table 3).

The value and direction of the correlation coefficients presented in Table. 3 indicate some relevant results, too. Indeed, the lower heart rate at rest state, during and after physical loading is, the higher result in pulling up is. The correlation coefficients range from -0.638 to -0.885 $(\mathrm{p}<0.01)$.

Statistically reliable interrelations were detected between the result in shuttle run and values of $\mathrm{HR}$ in different states. The higher the pulse values are before, during and after the loading, the longer the execution time of the shuttle run is. It means the worse test result.

The indexes of physical fitness reveal a close interrelation between them. It is not related to the interrelation of the result when lifting legs from the position of hanging on the bar and result in shuttle run.

The most closely connected push-ups on cross bars and lifting legs from the position of hanging on the bar. The high correlation coefficient between them $(r=0.922$, $\mathrm{p}<0.01)$ proves these tests to be equivalent. They reflect the level of strength endurance of the students.

The mathematical model of this dependence can be expressed as follows:

$$
y=-4.9924+1.1845 * x,
$$

where: $\mathbf{y}$ - is lifting legs from the position of hanging on the bar, number; $\mathbf{x}$ - push-ups on cross bars, number.

Characteristically, the result of push-ups is closely interrelated with heart rate in a rest state, that is, before loading (Figure 3).

The theoretical regression line, location of pullups individual values, magnitude and direction of the correlation coefficient $(\mathrm{r}=-0.885, \mathrm{p}<0.00001)$ indicate that functional status and level of the students' physical fitness are closely interrelated. Thus, improving their functional state in the dynamic of the pedagogical process determines the growth of speed and strength fitness.

\section{Discussion.}

We have managed to establish that the effectiveness of general physical fitness can be enhanced using the CrossFit training system. It includes the simultaneous practice of interval training, aerobic endurance, weightlifting, plyometrics, powerlifting, gymnastics, gaming sports $[5,14]$. It is known that the CrossFit Physical Training System is a brand-name fitness technique created by Greg Glassman. Moreover, it is a registered trademark of CrossFit organization, Inc., founded by Greg Glassman and Lauren Jenai in 2000 [5].

The improved results of physical fitness at the end of the experiment and the reduced HR at rest during and after physical loading proves the CrossFit method $[5,21]$ effectively enhances the functional state and physical fitness.

It is found that the servicemen have a statistically significant difference in functional indexes as a result of the registered control indexes during the experiment.

The HR before warming-up has decreased on average by $10 \%(\mathrm{P}<0.01)$. This indicates the presence of bradycardia and hypertrophy of the heart [22]. After a warming-up, the HR has decreased on average by $10 \%$ $(\mathrm{P}<0.01)$, after loading - by $7 \%(\mathrm{P}>0.05)$, after 1 minute of rest -by $8 \%(\mathrm{P}<0.01)$, after 3 minutes of rest - by $8 \%$.

The evaluation of the effectiveness of circular training proves an undoubted advantage of circular workouts.

The revealed changes, dependencies and model characteristics reflect the positive specificity of adaptive reorganization in the physical and functional fitness using the CrossFit method for 2.5 months.

The materials of our studies clarify and complement the results of studies of Ukrainian $[6,8,18]$ and foreign $[12,13,21]$ authors.

The elaborated models are the basis for developing an assessment system of physical fitness, differentiated

Table 3. Interrelations of indexes of physical fitness among themselves and with the level of HR in different states before and during muscular activity

\begin{tabular}{|c|c|c|c|c|}
\hline Indicators: & $\begin{array}{l}\text { Pull-ups, } \\
\text { number }\end{array}$ & $\begin{array}{l}\text { Push-ups on } \\
\text { cross bars, } \\
\text { number }\end{array}$ & $\begin{array}{l}\text { Lifting legs from the } \\
\text { position of hanging } \\
\text { on the bar, number }\end{array}$ & $\begin{array}{l}\text { Shuttle run } \\
10 \times 10 \mathrm{~m} \text {, } \\
\text { sec. }\end{array}$ \\
\hline Heart rate before warming-up, bpm ${ }^{-1}$ & $-0.885^{* *}$ & $-0.679 * *$ & $-0.673^{*}$ & 0.506 \\
\hline Heart rate after warming-up, $\mathrm{bpm}^{-1}$ & $-0.735 * *$ & -0.441 & -0.424 & $0.649 *$ \\
\hline Heart rate after loading (10 sec.), bpm ${ }^{-1}$ & $-0.638^{* *}$ & -0.525 & -0.405 & $0.809 * *$ \\
\hline Heart rate after loading (1 $\mathrm{min}.), \mathrm{bpm}^{-1}$ & $-0.655^{* *}$ & -0.430 & -0.347 & $0.810 * *$ \\
\hline Heart rate after loading ( $3 \mathrm{~min}.), \mathrm{bpm}^{-1}$ & $-0.658 * *$ & $-0.560 *$ & -0.484 & $0.828 * *$ \\
\hline Pull-ups, number & & $0.751^{* *}$ & $0.819 * *$ & $-0.535^{*}$ \\
\hline Push-ups on cross bars, number & & & $0.922 * *$ & $-0.561^{*}$ \\
\hline $\begin{array}{l}\text { Lifting legs from the position of hanging on } \\
\text { the bar, number }\end{array}$ & & & & -0.460 \\
\hline
\end{tabular}

Note: ${ }^{*} p \leq 0.05 ; * * p \leq 0.01$. 


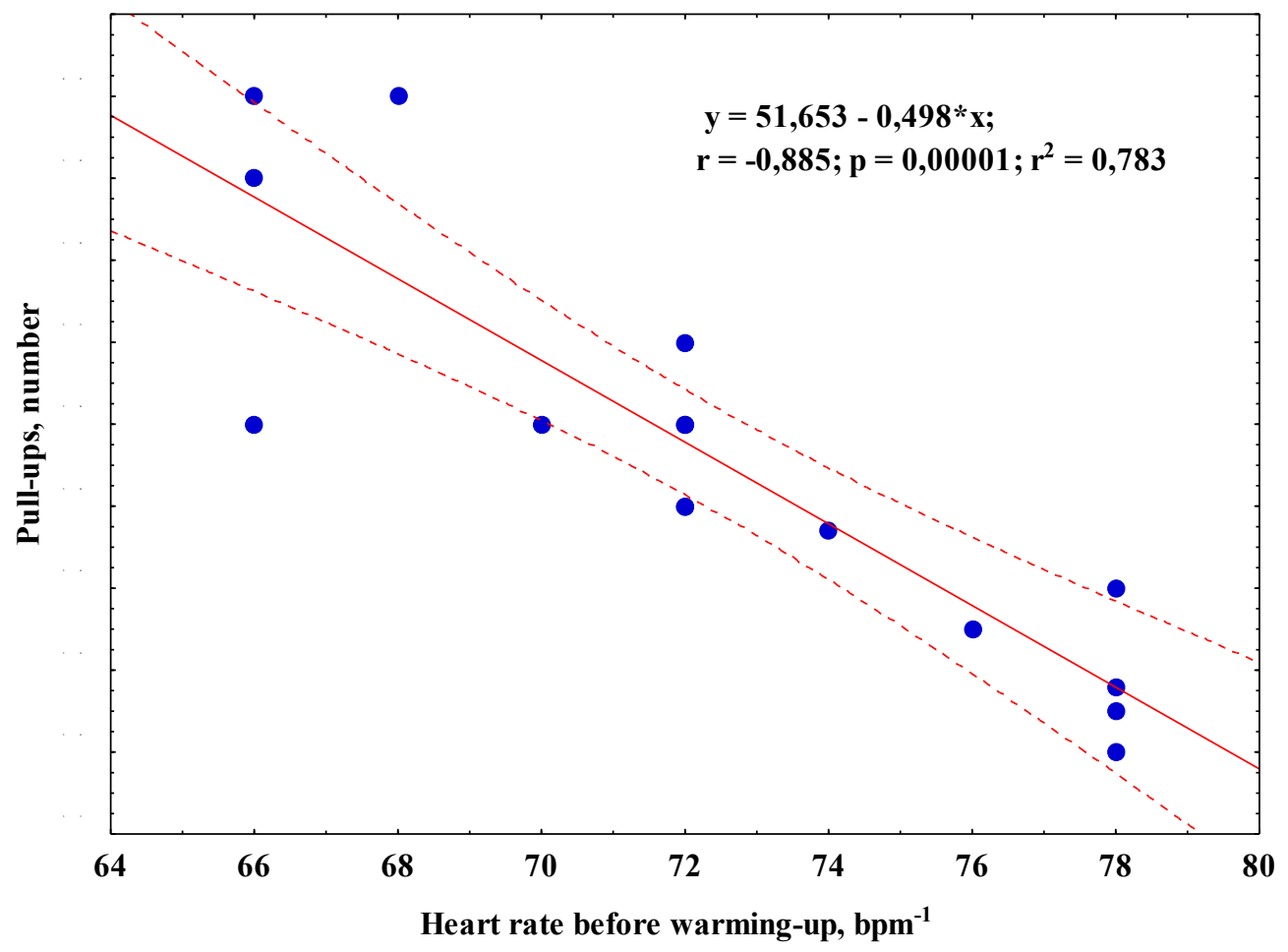

Figure 3. Regression model of dependence of result at pulling up on a crossbeam from heart rate at rest.

according to different criteria (training period, physical state during muscular activity, etc.).

The CrossFit method can optimize the training process in accordance to the main task of the period or stage of training. It can also provide optimal load dynamics, expedient combinations of different means and methods of training. In addition, it allows complying with the factors of pedagogical influence and achieving the necessary continuity in the development of various abilities.

\section{Conclusions.}

Thus, the CrossFit training positively affects the level of students' physical fitness, strengthens their motivation to physical education and sports activities. It also promotes the acquisition of knowledge about modern approaches to organizing physical training, skills and abilities of independent physical training.
Circular training in the CrossFit method increases the motional and emotional density of workouts. It makes workouts more diverse and interesting for students giving space for individual opportunities and personal initiative. Thus, it increases the motivation towards physical education.

The physical training with circular workouts gives positive results and contributes to the successful development of general physical fitness.

The prospects for further research include increasing the efficiency of the training process using CrossFit workouts and developing the evaluated and predictive models of fitness of military personnel.

\section{Conflict of interest.}

The authors state that there is no conflict of interest.

\section{References:}

1. Antoshkiv IuM. Improvement of professional and applied physical fitness of students of higher educational establishments of the MIA of Ukraine [PhD thesis]. Lviv; 2006. (In Ukrainian)

2. Domnshchak VV. Improvement of special physical training of the cadets of higher educational establishments of the MIA of Ukraine as a component of professional fitness of future militia officers. Pravo i Bezpeka, 2012; 1: 222-225. (in Ukrainian)

3. Zakorko IP. Special physical training: Organizational and methodological instructions for teaching the course. Kiev: RVV KIVS; 2001. (in Ukrainian).

4. Mozoliev O. About the formation of personal sense of physical improvement in future officers. Proceedings of the
Opened Scientific and Methodological Conference "Physical training of military". Kiev: NUPESU; 2003. P.147-150. (in Ukrainian)

5. CrossFit Level 1 Certificate Course. Participant Handbook. Version 8.6. 2019. [cited 2019 July 01]. Available from: http://library.crossfit.com/free/pdf/CFJ_L1_Training Guide Russian.pdf (in Russian).

6. Koval'chuk AM, Antoshkiv IuM, Ias'kiv IuIe. Analysis of evaluation system of physical fitness level of cadets of higher educational establishments of the MIA of Ukraine during the period of studies. Proceedings of the 4 Regional Scientific Conference. Lviv; 2007. P. 45-48. (in Ukrainian)

7. Pichugin MF, Griban GP, Romanchuk VM. Physical education of servicemen. Zhytomyr: ZVI NAU, 2010. (in Ukrainian) 
8. Sergiienko IuP, Lavrent'iev OM, Andrieianov AM. Psychological and pedagogical aspects of the of physical fitness level of cadets of law-enforcement bodies of Ukraine. Visnik Chernigivs'kogo nacional'nogo pedagogichnogo universitetu, 2011; 1 (91): 422-426. (in Ukrainian)

9. Travnikov A. Operational hand-to-hand fighting in the KGB system. Rostov-on-Don: Phoenix; 2006. (In Russian)

10.Anatskyi R, Kolomiitseva O, Cretu M, Potop V. Methodical basis of training of cadets for the military applied heptathlon competitions. Physical Education of Students. 2017;21(6):255-61. https://doi.org/10.15561/20755279.2017.0601

11. Claudino JG, Gabbett TJ, Bourgeois F, Souza H de S, Miranda RC, Mezêncio B, et al. CrossFit Overview: Systematic Review and Meta-analysis. Sports Medicine - Open, 2018;4. https://doi.org/10.1186/s40798-018-0124-5

12.Bellar D, Hatchett A, Judge LW, Breaux ME, Marcus LB. The relationship of aerobic capacity, anaerobic peak power and experience to performance in CrossFit exercise. Biol Sport, 2015;32(4):315-320. https://doi.org/10.5604/20831862.1174771

13.Butcher SJ. Do physiological measures predict selected CrossFit ${ }^{\circledR}$ benchmark performance? J Sports Med., 2015;6:241-247 https://doi.org/10.2147/OAJSM.S88265

14.Smith MM, Sommer AJ, Starkoff BE, Devor ST. Crossfitbased high-intensity power training improves maximal aerobic fitness and body composition. Journal of Strength
\& Conditioning Research, 2013; 27 (11): 3159- 3172. https://doi.org/10.1519/JSC.0b013e318289e59f

15.Romanchuk S. Physical training of land forces of Armed Forces of leading UN countries. Moloda sportivna nauka Ukraini. 2010; 14(2): 120-130. (in Ukrainian)

16.Kislenko Dmitro, Iukhno Iurij, Khmel'nic'ka Irina. Functional Readiness of the Students from the Institute for State Guard Management of Ukraine. Teoriia i metodika fizicheskogo vospitaniia $i$ sporta. 2018; 1: 49-56. (in Ukrainian) https://doi.org/10.32652/tmfvs.2018.1.141794

17.Pavlova I., Zastavska O. Influence of CrossFit Training on the Mental Condition and Quality of Life of Young People. Physical Education, Sports and Health Culture in Modern Society, 2019;(1 (45): 62-70. https://doi.org/10.29038/2220-7481-2019-01-62-70

18.Lushchak AR. Optimization of psychophysical fitness of cadets higher educational establishments of the MIA of Ukraine. [PhD thesis]. Lviv: LSUPC; 2001. (in Ukrainian)

19.Sudakov KV. Body functional systems. Moscow: Medicine; 1987. (In Russian)

20.Borovikov VP, Ivchenko GI. Prognostication in system STATISTICA in Windows. Moscow: Finance and Statistics; 2006. (in Russian)

21.Cooper TJ, Canto P. CrossFit training for law enforcement. CrossFit Journal Article, 2007; 61: 7-12.

22.Karpman BL, Belocerkovskij ZB, Gudkov IL. Testing in sport medicine. Moscow: Physical Culture and Sports; 1988. (in Russian)

\section{Information about the authors:}

Pryimakov 0.0.; (Corresponding author); http://orcid.org/0000-0003-0351-486X; alprim7491@gmail.com; Faculty of Physical Culture and Health Promotion, Szczecin University; al. Piast 40B, Block 6, 71-065 Szczecin, Poland.;

Kyslenko D.P.; http://orcid.org/0000-0001-6929-4236 ; kyslenko.d@gmail.com ; Institute of Management of state protection of Ukraine of Taras Shevchenko national University of Kyiv; St. P. Bolbochan, 8, 01014, Kyiv, Ukraine.

Yukhno Y.O.; http://orcid.org/0000-0002-1320-4075; yukhnoyuriy@ukr.net; National University of Physical Education; and Sport of Ukraine;; Fizkultury str. 1, Kiev, 03680, Ukraine.

Eider E.; http://orcid.org/0000-0002-8401-6442; sekretariat.wkfipz@univ.szczecin.pl; ${ }^{1}$ Faculty of Physical Culture and Health Promotion, Szczecin University; al. Piast 40B, Block 6, 71-065 Szczecin, Poland.

\section{Cite this article as:}

Pryimakov OO, Kyslenko DP, Yukhno YO, Eider E. Circular training as a means for improving physical skills in future security specialists in higher education institutions of Ukraine.. Physical education of students, 2019;23(5):262-268. https://doi.org/10.15561/20755279.2019.0508

This is an Open Access article distributed under the terms of the Creative Commons Attribution License, which permits unrestricted use, distribution, and reproduction in any medium, provided the original work is properly cited http://creativecommons.org/licenses/by/4.0/deed.en

Received: 28.07.2019

Accepted: 03.09.2019; Published: 26.10.2019 